\title{
La autopuesta en peligro de la víctima como factor atenuante de la responsabilidad civil*
} Self-endangerment by the victim as an
attenuating factor in civil liability

\section{Jorge Rivero Evia**}

\section{RESUMEN}

La autopuesta en peligro de la víctima es una causa de exclusión del delito que ha sido reconocida por tribunales penales de diversas naciones europeas. Esa institución penal se asimiló al derecho civil mexicano a raíz de la interpretación que la Suprema Corte de Justicia de la Nación verificó del artículo 1100 del Código Civil del Estado de Yucatán. En virtud de ello, la conducta negligente de la persona encargada del cuidado de una menor de edad (quien a su vez realizó una actividad temeraria) incide directamente en el reparto de la responsabilidad civil entre los agentes del daño y la víctima de este. Así, se observa la existencia de vasos comunicantes entre las diversas ramas del derecho.

PALABRAS CLAVE: Victimodogmática, victima, autopuesta en peligro, derecho civil de daños, concurrencia de culpas.

\begin{abstract}
Self-endangerment by the victim has been recognized as grounds for criminal exemption by criminal courts in various European nations. This legal institution was assimilated into Mexican civil law based on the interpretation that the Supreme Court of Justice of the Nation approved in Article 1100 of the Civil Code of the State of Yucatán. By virtue of this, the negligent conduct of the person charged with the care of a minor (who, in turn, has engaged in reckless activity) directly impacts on the allocation of civil liability among both the agents and victim of the damages. Therefore, the existence of communicating vessels among the various branches of the law is observed.
\end{abstract}

KEY WORDS: Victimodogmatic/Victimodogmatics, Victim, Self-endangerment, Civil right to damages/Civil tort law, contributory fault.

\footnotetext{
* Artículo de investigación. Recibido el 18 de septiembre de 2018 y aceptado para su publicación el 6 de mayo de 2019.

** Magistrado Presidente de la Sala Civil y Familiar del Tribunal Superior de Justicia del Estado de Yucatán, México. (jriverev@yahoo.com) orcid.org/0000-0002-8319-1206
} 


\section{SUMARIO}

1. Introducción

2. La formulación del principio victimodogmático

3. Repercusiones en el ámbito del derecho civil en México

4. Conclusiones

\section{Introducción}

Corren nuevos tiempos respecto a la consideración de la responsabilidad civil. Los diversos formantes jurídicos, el ideario colectivo y el sentir de los propios jueces -como respuesta por excelencia del Estado ante un hecho que lesiona bienes jurídicos- hacen que el sistema se vaya multiplicando en una serie de posibles consecuencias jurídicas que trascienden a lo tradicional y al ámbito específico del derecho civil. Tal es el caso de la autopuesta en peligro de la víctima, institución ampliamente desarrollada en el derecho penal (principalmente en Europa) que cobra aplicación en el derecho civil de daños.

¿Puede influir la conducta temeraria de la víctima en la responsabilidad civil, a través de la denominada "autopuesta en peligro"? ¿Qué sucede cuando la víctima que actúa temerariamente es menor de edad y se le ocasionan daños en un evento con ocasión del empleo de aparatos riesgosos? ¿Qué consecuencias tendría, en su caso, la autopuesta en peligro en el ámbito civil? ¿Excluye al ilícito o atenúa la sanción?

El trabajo aquí expuesto se justifica para intentar dar una respuesta a tales interrogantes. Pretende una primera aproximación al tema de la autopuesta en peligro en sede civil. Aunque, desde luego, no se agota, se presentan notas introductorias con base en el estudio de caso paradigmático acontecido en el estado de Yucatán. La metodología utilizada es la de un estudio de caso y el

346 ejercicio de derecho comparado, donde se enlazan conceptos propios de la victimología, del derecho penal y del derecho civil.

\section{La formulación del principio victimodogmático}

En primer orden, debemos hablar de qué es la victimología. Este término apareció, como tal, en la década de 1940; su nacimiento como disciplina científica se vincula a la preocupación de algunos cultivadores de la criminología y de la sociología criminal por la víctima del delito, su personalidad y, sobre todo, 
por su relación con el delincuente. Se asevera que constituye "la más moderna de las disciplinas científicas que se ocupan del fenómeno criminal". ${ }^{1}$

Todos los códigos penales se han visto influidos por el actuar del ser humano. De ahí que pongan límites a su capacidad, a las formas de obrar y omitir actos; las excusas absolutorias de ese obrar y en su caso, las atenuantes correspondientes; el laberinto, en fin, entre pena y culpabilidad; imputabilidad y su contrario, entre otros. Se trata de calibrar y frecuentar las formas que pueden asumir las distintas conductas. Los criminólogos, a su vez, pretenden establecer las condiciones de estudio interdisciplinario a favor de nuevas técnicas y hallazgos científicos, concernientes al conocimiento del drama penal, sus actores, factores predisponentes de la sociedad posindustrial en sí, sin dejar de lado los datos estadísticos.

Entre penalistas y criminólogos se suelen producir variadas controversias. Mientras ello ocurre, para enriquecer el ámbito de estudio, aparece la victimología, con su ponderación en la víctima. Así, intenta observar el fenómeno conductual que lleva al delito, desde la óptica y perspectiva de la víctima, siempre en relación con el victimario. ${ }^{2}$

A pesar de la aparición de la victimología a mediados del siglo $\mathrm{xx}$, cuando se alude al papel de las víctimas, en general se está abordando un tema tan antiguo como la propia humanidad. Este se ha presentado en todas las civilizaciones y religiones, y ha sido ampliamente documentado por los clásicos; incluso se encuentra en el folclore de cada país.

Benjamín Mendelsohn fue el creador del vocablo victimología. Se dice que el primer trabajo sistematizado en torno a las víctimas fue realizado por él, al llevar a cabo un estudio sobre el delito de violación. Mendelsohn atrae la atención sobre la víctima, cuestiona el desinterés con que ha sido tratada y señala que no puede hacerse justicia sin tomarla en cuenta. Consideró que, para contrarrestar esto, era necesario crear una ciencia independiente: la victimología. De esta manera, comenzó a crear algunos conceptos y definiciones victimológicas. ${ }^{3}$

A su vez, Hans von Hentig, otro de los precursores de los estudios científicos sobre la víctima del delito, realizó en su obra intitulada The criminal and his victim, el examen de la contribución de la víctima a la génesis del delito.

\footnotetext{
${ }^{1}$ Landrove Diaz, Gerardo, La moderna victimología, Valencia, Tirant lo Blanch, 1998, p. 20.

2 Neuman, Elias, Victimología. El rol de la víctima en los delitos convencionales y no convencionales, México, Cárdenas Editor, 1992, pp. 21-22.

${ }^{3}$ Rodriguez Manzanera, Luis, Victimología. Estudio de la víctima, México, Porrúa, 2000, p. 9.
} 
Como ha señalado Neuman, ${ }^{4}$ el pensamiento de Mendelsohn va mucho más allá que el de von Hentig. Efectivamente, se ocupa de toda víctima y de todos los factores que provocan su existencia; afirma que la victimología no debe interesarse solo por las víctimas de los delitos, sino también por las víctimas de otras catástrofes (así, naturales, como inundaciones o terremotos), pues el delictivo implica solo uno de los factores de victimización. Tal planteamiento implica una mayor amplitud, por lo cual vincula a esa disciplina más hacia un estudio de las víctimas y de la victimización.

Por lo anterior, surgen dos tipos de victimología: la penal y la general. El interés de los primeros victimólogos continúa siendo una de las corrientes internas de la victimología actual. Esta corriente ha sido llamada victimología penal, en contraste con la victimología general. Para los simpatizantes de la victimología penal, el panorama está definido por el derecho penal, con lo cual la victimología estudia a las víctimas de incidentes definidos por el derecho penal. La agenda de investigación de esta corriente victimológica combina problemas concernientes a la realización de delitos y al papel de la víctima en el proceso penal. La victimología penal mira hacia la interacción dinámica entre víctima y ofensor.

La segunda corriente principal es comúnmente llamada victimología general, como la victimología penal, esta corriente también fue explícitamente definida por el multicitado Mendelsohn. En una de sus publicaciones de la posguerra (1956) Mendelsohn se dedicó a un estudio general de lo que se llama "victimidad", con la visión de reducirla por medio de prevención y asistencia a las víctimas. En trabajos posteriores, habló de establecer clínicas para víctimas, pues la asistencia a las víctimas debería basarse en una teoría de rehabilitación personal, social y cultural.

El interés de Mendelsohn no se fijó más en el crimen y su prevención, sino en la prevención y alivio de la victimidad en lato sensu. No solo debería considerarse a las víctimas del delito o del abuso de poder como sujetos de estudio, sino también a las víctimas de accidentes, desastres naturales y "otros actos de Dios". Mendelsohn se dedicó al desarrollo de la victimología general como una disciplina totalmente aparte, independiente de la criminología o del derecho penal, la cual debería protagonizar el gobierno para minimizar el sufrimiento humano.

En recientes fechas, mucha investigación se ha realizado sobre las víctimas de violaciones a los derechos humanos y los mejores métodos de reparación y asistencia. Asimismo, han proliferado los programas de asistencia a víctimas de accidentes de tránsito o de desastres naturales. Es por esta razón que la

${ }^{4}$ Citado por Landrove Diaz, Gerardo, La moderna victimología, Valencia, Tirant lo Blanch, 1998, p. 27. 
corriente de la victimología que se enfoca a la asistencia es comúnmente llamada victimología general. Esta tendencia difiere de la victimología penal no solo en su definición, sino en el panorama de investigación primordialmente referente a la asistencia, por encima de la génesis de la victimización.

De tales postulados se origina la victimodogmática. Por ser esta una noción cercana a la materia penal, conviene el previo análisis de lo que se entiende por dogmática jurídico-penal.

La dogmática penal, o sea, el análisis del delito a partir de la ley penal en forma sistemática, la debemos al jurista alemán Franz von Liszt, expuesta en su obra Tratado de Derecho Penal. Liszt recoge las ideas de las escuelas clásica y positivista, y aplica el método naturalista que estaba en boga a fines del siglo xIx. Se aboca al estudio del Código Penal Alemán de 1871, para desprender de dicho código la estructura del delito, con lo cual nació la dogmática jurídico-penal, es decir "el conocimiento del delito a través del dogma, de la ley". ${ }^{5}$

El penalista mexicano Francisco Pavón Vasconcelos define a la ciencia del derecho penal como "el conjunto sistemático de conocimientos extraídos del ordenamiento jurídico positivo, referentes al delito, al delincuente y a las penas y medidas de seguridad". Por lo tanto, su objeto lo constituye el derecho penal y de ahí que se le designe también con el nombre de dogmática jurídico-penal. $^{6}$

En tal virtud, dogmática jurídico-penal y ciencia del derecho penal son vistas como sinónimos y constituyen el estudio del contenido de aquellas disposiciones que, en el seno del ordenamiento jurídico positivo, conforman el derecho penal. Es decir, estamos frente a un estudio integral del fenómeno criminal representado en la norma.

Ahora bien, si en su calidad de ciencia la victimología se encarga del estudio de la víctima -o sea, la persona que sufre un daño por culpa ajena, culpa propia o causa fortuita-, debe responderse a la interrogante de por qué se es víctima, cómo atender a esta y qué estrategias habrán de implementarse a fin de evitar la victimización y, en su caso, repararla. Una ciencia con tales alcances no podía quedar en un segundo plano y, por ende, presenta hoy día un alto grado de penetración en el sistema de justicia. ${ }^{7}$

Así, soluciones dogmáticas tan relevantes como la imputación o no del tipo objetivo pasan por considerar el comportamiento de la víctima en la comisión

\footnotetext{
${ }^{5}$ Orellana Wiarco, Octavio Alberto, Teoría del delito. Sistemáticas Casualista, Finalista y Funcionalista, México, Porrúa, 2000, p. 9.

${ }^{6}$ Pavón Vasconcelos, Francisco, Derecho Penal Mexicano, México, Porrúa, 2005, p. 23.

7 Ontiveros Alonso, Miguel, Derecho Penal. Parte General, México, Ubijus, 2017, p. 46.
} 
del hecho punible. ${ }^{8}$ Esto es precisamente lo que se pretende con la victimodogmática: demostrar que la víctima no es solo un "sujeto pasivo", "un objeto de prueba”, sino un ser relacional ${ }^{9}$ y que, por ende, tiene una participación en el mundo exterior, con lo cual puede variar la estructura del delito y el quantum de la pena.

En esta tesitura, la figura de la víctima constituye objeto de preocupación de diversas cuestiones dogmáticas que últimamente se agrupan bajo el rótulo de "victimodogmática". Estas aproximaciones ocupan una posición especial en comparación con las aportaciones doctrinales examinadas hasta el momento. Ello por varios motivos: en primer lugar, se trata de una tendencia, de una aproximación, de un modo de ver la figura de la víctima, más que de una formulación dogmática concreta para el problema de la intervención de la víctima. En segundo lugar, esta configuración difusa y amplia de las figuras victimodogmáticas viene motivada, sobre todo, por el hecho de que estas constituyen una reacción dentro de la dogmática a una evolución iniciada en otras disciplinas distintas de la ciencia del derecho. En tercer lugar, este carácter difuso de la victimodogmática - que aún se halla en sus inicios- es probablemente también la razón de que el debate sobre estas aportaciones sea en gran medida con argumentaciones más cercanas a las reflexiones de política criminal que a la discusión dogmática.

En todo caso, las especiales características de la victimodogmática aconsejan seguir un método de exposición algo distinto al utilizado respecto de otras aproximaciones. Intentan esbozar los rasgos esenciales del panorama en el que surge la victimodogmática antes de abordar sus propuestas dogmáticas. ${ }^{10}$

La orientación victimodogmática adopta como punto de partida de sus consideraciones que el derecho penal sirve a la protección de bienes jurídicos y que, por tanto, solo estará legitimada la amenaza penal cuando con ellas se trate de proteger bienes jurídicos. Además, con base en el carácter fragmentario

${ }^{8}$ Ontiveros Alonso, Miguel, Derecho Penal. Parte General, México, Ubijus, 2017, p. 46.

9 Bonet Esteva, Margarita, La víctima del delito (la autopuesta en peligro como causa de exclusión del tipo de injusto), Madrid, McGraw Hill, 1999, p. 20. "La concepción relacional, o comunicativa, de víctima significa que ésta no debe ser contemplada como un mundo aislado y concentrado sobre sí mismo, sino que las víctimas son seres en movimiento que entran en contacto con el mundo exterior y, muy especialmente, con el autor y los hechos que éste lleva a cabo. De este pensamiento se deriva que no es recomendable examinar autor y víctima sin determinar si existen puentes de relación entre ambos que puedan extraerse de sus comportamientos en los hechos delictivos."

${ }^{10}$ Cancio Meliá, Manuel, Conducta de la víctima e imputación objetiva en Derecho Penal. Estudio sobre los ámbitos de responsabilidad de víctima y autor en actividades arriesgadas. Barcelona, J. M. Bosch Editor, 2001, p. 221. 
del derecho penal, ${ }^{11}$ así como en los principios de subsidiariedad y ultima ratio, este podrá intervenir para proteger bienes jurídicos cuando no existan otras posibilidades de protección. Es aquí donde se incluye la perspectiva de la víctima, la cual posee también sus propios medios de autoprotección y podría hacer uso de ellos para proteger el bien jurídico del que es portadora.

En este sentido, se elabora un principio de autorresponsabilidad de la víctima (Selbstverantwortungsprinzip): cuando la víctima, por iniciativa propia, renuncia a hacer uso de las medidas de autoprotección de las que dispone y, por tanto, abandona el bien jurídico, ha de eximirse de responsabilidad penal al autor. No se hará acreedor de protección penal el portador de un bien jurídico, si él mismo no lo protege con los medios que tiene al alcance para hacerlo. En virtud de esta idea, el principio de subsidiariedad de la intervención penal no solo se refiere a la relación del derecho penal con otros medios estatales, sino que también es subsidiaria respectos de las posibilidades privadas de autoprotección. ${ }^{12}$

Son dos las aportaciones victimológicas que más han llamado la atención a los teóricos del derecho penal. La primera de ellas es la llamada concepción relacional de la "pareja penal". Esto se debe a que tal orientación obliga a una interpretación dinámica del binomio autor-víctima, por lo cual se da entrada a la observación de cuál es la aportación (movimiento) de la víctima en la realización de un delito. En otras palabras, consiste en cómo debe ser tratado el comportamiento de la víctima, desde el punto de vista dogmático. Para ello, será ineludible la previa elucidación de cuáles son los comportamientos relevantes para el derecho penal y cuál es su sede categorial. ${ }^{13}$ Ello conduce a la segunda aportación, denominada la autopuesta en peligro.

Acorde a lo ya expuesto, se puede afirmar que la víctima no tiene siempre un papel pasivo y estático, y que los tiempos en los que se ignoraba por completo esa actuación de la víctima ya pasaron. Resulta evidente que la preocupación de los operadores jurídicos por el tratamiento y ubicación del comportamiento imprudente de la víctima ha sido una constante.

\footnotetext{
11 Jescheck, Hans Heinrich, Tratado de derecho penal. Parte general, Granada, Editorial Comares, 1993, p. 45. "El derecho penal tiene carácter fragmentario, según una famosa expresión de Binding. No contiene ningún sistema exhaustivo de protección de bienes jurídicos, sino que se centra en determinados puntos esenciales seleccionados conforme al criterio de 'merecimiento de la pena'. Mientras que todavía Binding consideraba la autolimitación del legislador como un 'grave defecto de su obra', hoy la limitación de la punibilidad a las acciones que por su peligrosidad y reprochabilidad requieren y merecen claramente, en interés de la protección social, la pena pública, aparece como un mérito y un distintivo del Estado liberal de derecho."

${ }^{12}$ Alastuey Dobón, M. Carmen, La reparación a la víctima en el marco de las sanciones penales. Valencia, Tirant lo Blanch, 2000, pp. 42-43.

${ }^{13}$ Bonet Esteva, Margarita, La víctima del delito (la autopuesta en peligro como causa de exclusión del tipo de injusto), Madrid, McGraw Hill, 1999, p. 62.
} 
Surge así la autopuesta en peligro para excluir la responsabilidad del autor cuando la víctima decide voluntaria y libremente hacer frente al peligro asumiendo sus consecuencias, es decir, en aquellos casos en los que puede elegir sin interferencias ajenas entre enfrentarse al riesgo o no hacerlo. ${ }^{14}$

Son tres los presupuestos señalados para la configuración de una acción a propio riesgo: a) que la víctima tenga el poder de decidir si asume el riesgo y el resultado; b) que sea auto responsable, es decir, que conozca o tenga posibilidad de conocer el peligro que afronta con su actuar; y c) que el actor no tenga posición de garante respecto de ella. ${ }^{15}$

Es en dos sentencias (3-6-89 ${ }^{16}$ y 17-7-90) ${ }^{17}$ que el Tribunal Supremo Español comenzó a vislumbrar un aspecto desconocido de la conducta de la víctima: el comportamiento de esta como factor generador o incrementador del riesgo y el comportamiento de aquella como introducción imprudente en un riesgo ajeno. Asimismo, en otras naciones se siguió un derrotero similar. ${ }^{18}$

${ }^{14}$ González Cussac y Mira Benavent, "Ámbito de responsabilidad de la víctima y teoria de la imputación objetiva", en La Ciencia del Derecho Penal ante el nuevo siglo, libro homenaje al profesor doctor don José Cerezo Mir, tomo 1, Madrid, Tecnos, 2002, p. 723.

${ }^{15}$ Sánchez Zapata, Sebastián Felipe, Actuación de la víctima e imputación objetiva: comentario a la sentencia de la Corte Suprema de Justicia 36842 del 27 de noviembre de 2013, Nuevo Foro Penal, junio, 2014, vol. 10, núm. 82, p. 203.

${ }^{16}$ STS 3/6/89: El procesado comprueba que el viento sopla en dirección contraria a la carretera y ordena -una de las labores agrícolas habituales en dicha época del ario- la quema de rastrojos a sus operarios. El viento, de forma imprevisible, entrado el mes de agosto y en territorio llano, gira $180^{\circ}$, invadiendo el humo la carretera a pesar de los esfuerzos del procesado y sus operarios por controlar el fuego. Por todo ello, la visibilidad era mínima, a pesar de lo que dos coches se adentraron en la cortina de humo y acabaron por colisionar. El agricultor que ordenó prender el fuego quedó exento de responsabilidad penal porque actuó con la diligencia debida y, además, las víctimas se comportaron de forma contraria a la más elemental de las prudencias. Con respecto a la valoración que en la sentencia se hace del comportamiento de las víctimas, se parte en esta de que los conductores de los coches (víctimas) interfirieron en el nexo causal, rompiendo cualquier imputación posible. Esta intervención de las victimas es tan relevante porque, advirtiendo semejante fuente de peligro que otro ha creado, se introducen en esa esfera de riesgo y lo asumen de forma autor-responsable. Esa intromisión de las víctimas borra la primera de las relaciones entre la fuente de peligro y su causante. Podría decirse que, ante ese ámbito de riesgo concreto, pero más amplio, las víctimas optan injustificadamente por incrementar su propio riesgo individual concreto de que se produzca un resultado lesivo.

${ }^{17}$ STS 17/7/90. En una fiesta en la que los allá presentes ingirieron bastante alcohol, un joven que había accedido al cuerpo de la Guardia Civil recientemente hace constantes alardes con la pistola que se le había entregado y acepta una apuesta que consiste en acertar a la botella que otro joven -también ebrio- sostenía en la mano, con tan mala fortuna que cuando dispara, de forma un tanto sorpresiva, coincide con el movimiento de quien sostenía la botella para limpiarse unas manchas de vino. En conclusión, el disparo hirió al joven en el tórax y le causó la muerte.

${ }^{18}$ Como lo demuestra Bonet Esteva, al exponer la casuistica alemana e italiana, comparada con la española. Véase Bonet Esteva, Margarita, La víctima del delito (la autopuesta en peligro como causa de exclusión del tipo de injusto), Madrid, McGraw Hill, 1999, p. 62. 


\section{Repercusiones en el ámbito del derecho civil en México}

Se debe destacar que el derecho romano acuñó el aforismo volenti non fit iniuria, que significa que a quien consiente no se le ocasiona lesión o daño. ${ }^{19}$ Es decir, la conducta de la víctima es relevante en un hecho que genera daños. Asimismo, se denota que también los romanos identificaron como fuente de obligación civil aquella que nace ex delicto. En efecto, partiendo de la diferenciación entre los delicta privata y los delicta publica. Los primeros refieren a los actos ilícitos que ocasionaban daño a la propiedad o a la persona de los particulares, pero sin turbar directamente el orden público; en tanto que los segundos sí afectaban el interés general.

Así pues, se consideró como delitos privados al furtum o hurto, al daño causado "injustamente", al robo y daño acompañados de violencia y a la injuria. En lo que interesa, el daño causado injustamente fue castigado por la Ley Aquilia y consistió en que cuando una persona causa sin derecho un perjuicio a otra, atacando su propiedad, la equidad quiere que haya reparación en provecho de la víctima. Los romanos llegaron a esa figura progresivamente; disposiciones especiales se dictaron primero para los daños más frecuentes y más graves; con posterioridad, el pretor, por extensiones sucesivas, ensanchó el derecho civil y permitió la reparación del perjuicio causado fuera de las condiciones fijadas en la ley. ${ }^{20}$

Nuestra legislación civil adopta el principio derivado de lo anteriormente referido: alterum non laedere (no dañar a otro), ${ }^{21}$ expresado en los artículos 1910 y 1913 del Código Civil Federal (con idéntica redacción en los artículos 1097 y 1100 del Código Civil del Estado de Yucatán).

En los antiguos códigos civiles federales, especialmente en el de 1870, se regularon dentro del capítulo de la responsabilidad civil las hipótesis de la falta de cumplimiento de contrato y de los actos u omisiones que están sujetos a la responsabilidad por la ley. Esto quiere decir que el legislador de 1870 dispuso la responsabilidad contractual y la extracontractual de ilícitos en un mismo capítulo. Siguiendo la técnica alemana reflejada en el código suizo, el actual artículo 1910 establece una obligación: la de reparar el daño causado

\footnotetext{
${ }^{19}$ Elias Azar, Édgar, Frases y expresiones latinas, México, Porrúa, 2006, p. 427.

${ }^{20}$ Petit, Eugene, Tratado elemental de Derecho Romano, México, Editora Nacional, 1966, pp. 454-460.

${ }^{21}$ Pérez Fuentes, Gisela Maria; Gallegos Pérez, Nidia del Carmen, "Clases de responsabilidad civil", en Gisela Maria Pérez Fuentes (coord.), Temas actuales de responsabilidad civil, México, Tirant lo Blanch, 2018, p. 73. La simple convivencia social obliga a las personas a respetar y no causar daño. Surge así un deber genérico de no dañar, por lo cual la violación del deber antes señalado genera responsabilidad como sanción. Este es el principio de la responsabilidad extracontractual; surge con independencia de que los sujetos de la relación que nace por el incumplimiento no hayan tenido un precedente o una relación anterior.
} 
cuando se obra ilícitamente o contra las buenas costumbres. Vinculando dicho numeral con el diverso 1913 (que regula la responsabilidad objetiva), se observa lo siguiente: a) No todo obrar ilícito es fuente de obligaciones, sino solo aquel que cause daño a otro; $b$ ) en ocasiones, aun sin ilícito se puede incurrir en responsabilidad (por el uso de aparatos riesgosos), y c) la ilicitud civil es diversa de la valoración penal, pues mientras que la primera hace referencia a la satisfacción de un interés privado, la segunda alude a un interés público destinado a la conservación social. ${ }^{22}$

Entonces, la responsabilidad civil conlleva la obligación de indemnizar por los daños y perjuicios causados por un incumplimiento a las obligaciones asumidas (fuente contractual) o por virtud de un hecho ilícito o riesgo creado (fuente extracontractual). De ahí que, de ser posible, la reparación del daño debe consistir en el establecimiento de la situación anterior a él o, cuando ello sea imposible, en el pago de daños y perjuicios. ${ }^{23}$

En lo que interesa al presente trabajo, la responsabilidad civil extracontractual puede ser de naturaleza: ${ }^{24}$

- Objetiva, derivada del uso de objetos peligrosos que crean un estado de riesgo para los demás, independientemente de que la conducta del agente no haya sido culposa (la cual se apoya en un elemento ajeno a la conducta) y de que no haya obrado ilícitamente.

- Subjetiva, la cual deriva de la comisión de un hecho ilícito que, para su configuración requiere de una conducta antijurídica, culposa y dañosa.

A su vez, el deber general de responder por situación de equidad que impone el derecho obliga a que la persona responsable no sea necesariamente la causante del daño, pues en estos casos la conducta culpable no tiene que ser probada por la víctima. La ley imputa culpa por omisión a la persona física o jurídica colectiva que debía tener bajo su cuidado a determinada persona $o$ animal, e incluso, cualquier cuerpo inanimado; esto es lo que se denomina culpa in vigilando. ${ }^{25}$

\footnotetext{
${ }^{22}$ López Monroy, José de Jesús, "Artículo 1910", Código Civil para el Distrito Federal en materia común y para toda la República en materia federal comentado. Libro cuarto, primera parte. 'De las obligaciones', tomo 4, México, Instituto de Investigaciones Jurídicas de la Universidad Nacional Autónoma de México - Miguel Ángel Porrúa, 1990, pp. 63-64.

${ }^{23}$ Pérez Fuentes, Gisela Maria; Gallegos Pérez, Nidia del Carmen, "Clases de responsabilidad civil", en Gisela María Pérez Fuentes (coord.), Temas actuales de responsabilidad civil, México, Tirant lo Blanch, 2018, p. 71.

${ }^{24}$ Pérez Fuentes, Gisela Maria; Gallegos Pérez, Nidia del Carmen, "Clases de responsabilidad civil", en Gisela María Pérez Fuentes (coord.), Temas actuales de responsabilidad civil, México, Tirant lo Blanch, 2018, pp. 71-72.

${ }^{25}$ Pérez Fuentes, Gisela María; Gallegos Pérez, Nidia del Carmen, "Clases de responsabilidad civil", en Gisela María Pérez Fuentes (coord.), Temas actuales de responsabilidad civil, México, Tirant lo Blanch, 2018, p. 73.
} 
Ahora bien, como se ha visto, en los últimos años, el principal polo de desarrollo doctrinal de la contribución de la víctima en el hecho ilícito ha residido en el ámbito de la victimología y del derecho penal; máxime que el consentimiento de la víctima como causa de exclusión del injusto ha sido expresamente incluido en las normas penales. Muestra de ello lo es la fracción tercera del artículo 15 del Código Penal Federal, ${ }^{26}$ figura que se replica en los códigos penales de las diversas entidades federativas.

A la par, en México, es cada vez más frecuente que la Suprema Corte de Justicia de la Nación (scJN) utilice el que hemos denominado "control de interculturalidad", ${ }^{27}$ verificando argumentos de derecho comparado y citando sentencias pertenecientes a culturas jurídicas extranjeras, cuando resuelve los casos que son sometidos a su jurisdicción. Así aconteció al fallar la Primera Sala el amparo directo en revisión 4555/2013, de cuya ejecutoria derivaron sendas tesis aisladas como resultado de la interpretación del artículo 1100 del Código Civil del Estado de Yucatán. ${ }^{28}$

El asunto seleccionado resulta por demás interesante, dado que la Primera Sala de la scJN, a fin de determinar los alcances del artículo citado (tildado de inconstitucional), aludió a que:

Diversos tribunales internacionales [sic] se han pronunciado en el sentido de que la culpa grave o inexcusable de la víctima o de quienes tienen a su cuidado a la víctima, cuando es menor de edad, puede dar lugar a la exoneración del agente. Asimismo, han señalado que cuando hay concurrencia de culpas, la indemnización debe atenuarse atendiendo al grado de culpabilidad de los involucrados. ${ }^{29}$

Lo anterior procede de que el artículo 1100 del Código Civil en trato no abarcaba ambos temas (imputación objetiva del resultado a quienes tienen a su cargo a la víctima menor de edad y la concurrencia de culpas), pues dicho numeral es del siguiente tenor:

\footnotetext{
${ }^{26}$ Artículo 15. El delito se excluye cuando: [...] Se actúe con el consentimiento del titular del bien jurídico afectado, siempre que se llenen los siguientes requisitos: a) que el bien jurídico sea disponible; b) que el titular del bien tenga la capacidad jurídica para disponer libremente del mismo, y c) que el consentimiento sea expreso o tácito y $\sin$ que medie algún vicio; o bien, que el hecho se realice en circunstancias tales que permitan fundadamente presumir que, de haberse consultado al titular, este hubiese otorgado el mismo.

${ }^{27}$ Véase: Rivero Evia, Jorge, Fundamentos de Derecho Intercultural, México, Tirant lo Blanch, 2017.

${ }^{28}$ Tesis primera 279/2014 y Tesis primera 280/2014, Gaceta del Semanario Judicial de la Federación, Décima Época, julio, 2014, pp. 164-165.

${ }^{29}$ Amparo directo en revisión 4555/2014, sentencia de 26 de marzo de 2014, Primera Sala de la SCJN, p. 25.
} 
Cuando una persona hace uso de sustancias, mecanismos, instrumentos o aparatos peligrosos por sí mismos, por su naturaleza explosiva o inflamable, por la velocidad que desarrollen, por la energía de la corriente eléctrica que conduzcan o por otras causas análogas, está obligada a responder del daño que cause, aunque no obre ilícitamente, a no ser que demuestre que ese daño se produjo por culpa o negligencia inexcusable de la víctima.

El caso concreto derivó de un accidente de tránsito en el cual una menor de edad, que transitaba abordo de una bicicleta por una céntrica calle de la ciudad de Mérida, Yucatán, colisionó con un autobús de transporte público. Con motivo de ese evento, la impúber sufrió amputación de uno de los miembros inferiores de su cuerpo (pierna derecha y parte de la cadera). Se substanció al respecto una causa penal, que derivó en una negativa de orden de aprehensión contra el conductor del automotor, la cual fue confirmada por la Sala Penal del Tribunal Superior de Justicia del Estado.

Asimismo, se verificó un enjuiciamiento civil, al ejercer la madre de la víctima, ${ }^{30}$ en representación de su hija, la acción de responsabilidad objetiva contra el chofer y la empresa propietaria del autobús. Ello con fundamento en el artículo citado ut supra. La acción fue fundada y procedente, motivo por el cual se condenó a los demandados al pago de una indemnización. Una de las defensas sostenidas era la atribución de responsabilidad a la progenitora, por no observar el correspondiente deber de cuidado, a pesar de ser sujeto garante de la seguridad y bienestar de la víctima. Dicho argumento no prosperó en la instancia del fuero común, toda vez que, si bien fue tema de agravio en el correspondiente recurso de apelación interpuesto por los demandados, la Sala Colegiada Civil y Familiar del Tribunal Superior de Justicia del Estado de Yucatán (sccF) lo declaró infundado. No obstante, en la alzada se redujo el monto de las reparaciones e indemnizaciones, por estimarse diversos déficits probatorios.

Con motivo de ello, se promovieron sendos amparos directos; en uno de ellos, la parte demandada (chofer y empresa de transporte) invocó la inconstitucionalidad del indicado artículo 1100 del Código Civil, argumento que desestimó el Tribunal Colegiado en Materias Civil y Administrativa del XIV Circuito, con residencia en Mérida, Yucatán (TCC). En esas condiciones, se acudió ante la Primera Sala de la scjn, a través del correspondiente recurso de revisión (ADR 4555/2913), en donde se resolvió que, si bien la norma impugnada no era

\footnotetext{
${ }^{30}$ Se aclara que la acción de responsabilidad civil objetiva (que incluyó la prestación de daño moral) fue ejercida por
} la progenitora de la víctima directa, en su representación, por ser esta última menor de edad, y no a título personal. 
inconstitucional, sí lo era la interpretación que de la misma verificaron tanto el tribunal colegiado como la sala de apelación. En el caso, se debía analizar la contribución de la víctima (menor de edad) a la producción del resultado, ya que de acontecer en la especie la figura de la culpa in vigilando, derivada de la falta de cuidado de sus progenitores, se podrían disminuir las indemnizaciones respectivas, al consolidarse la "concurrencia de culpas".

La Primera Sala de la scun, tras citar precedentes de España (Tribunal Supremo Sentencia 21793/1994; Sentencia 1949/1985; Sentencia (casación) 9647/1998; Sentencia 1075/1997), Italia (Tribunal Supremo, Caso Orecchia c. Geroni 17-oct-1964) e Inglaterra (Casos Lynch v. Nuroin-1841 y Gough v. Thorne-1964), indicó:

Como se puede observar, la jurisprudencia internacional [sic] no exonera a los menores de edad o a sus padres, de responsabilidad, cuando su conducta es causa de un accidente con un objeto o mecanismo peligroso. Más bien, valora la conducta de todas las partes involucradas, así como las circunstancias en las cuales tuvo lugar el accidente, para determinar si hay concurrencia de culpas, y graduar la responsabilidad de cada una de las partes en el incidente; en el entendido de que el agente conductor del mecanismo $u$ objeto peligroso solo es exonerado cuando demuestra que el accidente tuvo lugar por culpa exclusiva de la víctima y que fue diligente y tomó las precauciones necesarias para evitar el accidente, siempre y cuando, este haya sido previsible.

Derivado de ello, la scsn introduce al derecho civil una figura que encuentra su fundamento en el ámbito penal; a saber, la concurrencia de culpas y la autopuesta en peligro como causa de atenuación de la responsabilidad. Al no existir precedente directo en el derecho doméstico, se vio en la necesidad de acudir al precedente extranjero.

Lo anterior se plasmó con mayor claridad en la sentencia de 19 de agosto de 2015 emitida por la sccF en el toca 1271/2012 al cumplimentar la ejecutoria federal en comento (como quedó plasmado, la scjn revocó la diversa sentencia del Tcc), pues el amparo fue concedido para los siguientes efectos:

Dejar insubsistente el fallo dictado el trece de agosto de dos mil catorce, se emita uno nuevo, para que con base en los puntos de prueba que se desprendan de autos, considere, en este caso, que la parte demandada no demostró la culpa inexcusable de la víctima, en términos de lo que 
previene la última parte del artículo 1100 del Código Sustantivo de la materia, como tampoco que el agente conductor haya obrado con diligencia para evitar el percance, ponderando además, si la conducta de dicha víctima y la omisión de cuidado por parte de sus padres, constituyó una de las causas que dieron lugar al accidente y si en consecuencia, hay concurrencia de culpas; y de ser así, en esa hipótesis, disminuya la indemnización que legalmente corresponda, en razón del grado de culpabilidad que pudiera tener la menor lesionada y las personas que sobre ella ejerzan la patria potestad; debiendo mantener la declaratoria de procedencia de la acción de daño moral en contra de la parte demandada y avocándose al análisis de los motivos de agravio vertidos por la parte actora en su ocurso de apelación en torno al monto que corresponde a dicho concepto y, hecho que sea, resuelva, con plenitud de jurisdicción, lo que en derecho corresponda.

Con base en lo resuelto en la sentencia federal de mérito, la sccF interpretó del artículo 1100 del Código Civil del Estado de Yucatán que, para que se surta la responsabilidad civil objetiva, no es necesario que exista culpa alguna, pues su principio deriva de la equidad genérica. Esto es, que quien pretenda las ventajas de un avance tecnológico que le propicie comodidad, como es la utilización de un vehículo motorizado, debe acarrear las desventajas de reparar los daños que su uso cause.

Ello es propio de la sociedad postindustrial que nos toca vivir, conocida por la doctrina como sociedad del riesgo. ${ }^{31}$ La sociedad actual aparece caracterizada por la aparición de avances tecnológicos insólitos en la historia de la humanidad. El extraordinario desarrollo de la técnica ha tenido y sigue teniendo obviamente repercusiones directas en un incremento del bienestar individual. Sin embargo, conviene no ignorar sus consecuencias negativas. De entre ellas, la que aquí interesa resaltar es la configuración del riesgo de procedencia humana como fenómeno social estructural. En otras palabras, destaca el hecho de que buena parte de las amenazas a las cuales los ciudadanos estamos expuestos provengan precisamente de decisiones que otros conciudadanos adoptan en el manejo de los avances técnicos.

Así, la normatividad regula que, en caso de que tales conductas produzcan daños, estos sean reparados, generándose las acciones de responsabilidad objetiva y subjetiva. Como se ha visto, la diferencia entre la responsabilidad objetiva

\footnotetext{
${ }^{31}$ Beck, Ulrich, citado por Silva Sánchez, Jesús María, La expansión del derecho penal. Aspectos de la política criminal en las sociedades postindustriales, Madrid, Civitas, 2001, p. 21.
} 
y la subjetiva radica en que, mientras esta última implica negligencia, dolo o intencionalidad en la realización del daño, la responsabilidad objetiva se apoya en la teoría del riesgo, donde hay ausencia de intencionalidad.

Bajo esa perspectiva, los elementos de la responsabilidad objetiva son: a) que se use un mecanismo peligroso; b) que se cause daño, y c) la existencia de un nexo de causalidad entre el hecho descrito en el inciso a) y el daño referido en el inciso $b$ ).

La jurisprudencia de la scjn ha establecido que la responsabilidad objetiva es independiente de la culpabilidad del agente. Igualmente, ha definido que no se refiere solo a la persona física que manipula los mecanismos peligrosos, sino que, en casos como el de la especie en los que se ve involucrado el servicio de transporte público, comprende también a la persona moral que brinda ese avance técnico al conglomerado. Asimismo, se expresa en la jurisprudencia que no se requiere que en el manejo de tales mecanismos se obre ilícitamente, aunque el obrar lícito no exime de la responsabilidad. ${ }^{32}$

En ese sentido y en estricto acatamiento a la ejecutoria federal de referencia, la sccF concluyó que no le asistía la razón a los demandados cuando aducen que no se surte la acción de responsabilidad objetiva, en virtud de que las pruebas ofrecidas por ellos la desvirtúan. En su confesión, el chofer del camión expresó que fue la niña quien se impactó en su vehículo -lo cual no fue tomado en consideración por la resolutora- y que de las pruebas aportadas se demuestra que la culpa fue de la menor de edad.

La sccF determinó una importante salvedad contenida en la norma, consistente en exonerar de responsabilidad objetiva al agente cuando se demuestre que el daño se produjo por culpa o negligencia inexcusable de la víctima. La procedencia de la responsabilidad depende de que el uso del aparato sea la causa del daño ocasionado; de ahí que, si se comprueba que fue otra la causa que ocasionó el daño -el cual no pudo preverse o evitarse por el agente-, su responsabilidad disminuye o cesa, atendiendo al grado de diligencia que hayan tenido las partes.

Esto no significa que en forma invariable y absoluta pueda actualizarse la responsabilidad en el agente, sino que, ante la posibilidad de que haya concurrido otra causa al daño generado, obliga al juzgador a valorar las circunstancias particulares del caso y el acervo probatorio para determinar si opera una excluyente de responsabilidad o si la responsabilidad debe graduarse en función de las conductas de las partes. Esto entraña la obligación para el

\footnotetext{
32 Tesis 352, apéndice de 1995, Sexta Época, scjn, p. 237; Tesis 353, apéndice de 1995, Sexta Época, scjn, p. 237; Tesis 347, apéndice de 1995, Quinta Época, ScJN, p. 233.
} 
resolutor de tomar en consideración todo el cúmulo probatorio con el fin de determinar el grado de responsabilidad atribuible, tanto a la víctima como al agente encargado del uso del aparato peligroso.

En ese contexto, la sccF destacó que:

- El chofer del autobús no actuó diligentemente (por falta de comprobación de lo contrario) al conducir el mecanismo (automotor) que provocó las lesiones de la víctima.

- La empresa patrona no puso a disposición de su empleado los implementos necesarios para que este, a su vez, obrara diligentemente en el acontecimiento, y así evitara la producción del resultado.

- La madre de la menor damnificada incurrió en la figura denominada culpa in vigilando, al no ejercer debidamente el deber de cuidado respecto del bienestar de su hija, pues se evidenció que al momento del evento dañoso, la impúber se encontraba conduciendo una bicicleta sin su supervisión, debiendo responder por los daños que para sí misma se generó, derivados de la autopuesta en peligro latente según la interpretación que el Tribunal Colegiado de Circuito verificó respecto del artículo 1098 del Código Civil Estatal y sin que esto conlleve a la exoneración de los demandados.

Así, bajo tales premisas - responsabilidad tripartita (conductor, empresa y madre de la víctima)-, la sccF consideró que de las pruebas agregadas ${ }^{33}$ se evidenció la existencia de la generación de un riesgo no permitido ${ }^{34}$ (consistente en la tolerancia o no evitación de que un menor de edad tripule a bordo de una bicicleta sin supervisión y en no obrar diligentemente en la conducción de un autobús de transporte público) que potencia el ya de por sí riesgo natural en la conducción

${ }^{33}$ Confesión de la actora en la que aceptó que el día en que sucedieron los hechos no se encontraba con la menor de edad. Esto fue corroborado por el demandado físico, al dar contestación de la demanda, adminiculadas ambas con la prueba pericial ofrecida por la parte actora, quien valoró a la menor de edad. Se concluyó la existencia de huellas físicas en su cuerpo, ocasionadas con motivo del hecho de tránsito, así como las fotografias que obran en autos; medios de prueba que acreditan el percance ocurrido con intervención de la menor de edad, que el chofer demandado no obró con diligencia, pues no hizo nada por evitar el resultado; la empresa dueña del avance tecnológico generador del riesgo no puso al alcance del conductor los implementos mínimos para que estuviese en condiciones de evitar el resultado, así como la falta total de cuidado de parte de la actora del juicio, como madre y adulto responsable de la niña, al permitirle que condujera su bicicleta en una calle que era transitada por vehículos automotores.

34 "El concepto de riesgo permitido expresa una ponderación de los costes y beneficios de la realización de una determinada conducta. El cálculo también depende de la valoración previa, en la que necesariamente habrá que incluirse como premisa mayor la autocomprensión de la sociedad y el orden relativo de valores." Silva Sánchez, Jesús-Maria, La expansión del derecho penal. Aspectos de la política criminal en las sociedades postindustriales, Madrid, Civitas, 2001, p. 32. 
de vehículos en las arterias viales de una urbe como la del lugar de los hechos (Mérida, Yucatán).

En dicho riesgo, según la sccF, hay cooperación relevante de todas las partes del conflicto, conforme a la teoría de la equivalencia de las condiciones ${ }^{35} \mathrm{o}$ de la conditio sine qua non, conforme a la cual todas las condiciones concomitantes en un hecho tienen el mismo valor en la producción del daño. De tal manera, suprimiendo una de esas condiciones, lo lógico y natural sería la no verificación de ese daño. Es decir, de haber obrado diligentemente el conductor, no se habría producido el accidente de tránsito. De haber proporcionado la propietaria del mecanismo que produjo el daño todos los implementos idóneos y necesarios para la conservación de la unidad en óptimas condiciones para permitir una reacción inmediata del chofer, no hubiese acontecido la colisión. Y de no haberse permitido que la menor saliera sola con su bicicleta a la calle, no habría resultado lesionada.

En ese sentido, resulta imprescindible identificar las infracciones al deber de cuidado de las partes en conflicto, a fin de tasar o calibrar con criterio equitativo, su incidencia en la responsabilidad por el hecho acaecido.

$\mathrm{Al}$ respecto, la doctrina fija los criterios por seguir para delimitar la infracción del deber de cuidado: cognoscibilidad, previsibilidad y evitabilidad. ${ }^{36}$ La cognoscibilidad implica el distinto grado de conocimiento o desconocimiento de los factores de riesgo; a saber, contar con toda la información disponible para prever un resultado; considerar ese riesgo como probable o no, permisible o reprobado y, así, estar en miras de evitarlo.

En el sumario consta y aparece que la madre de la menor se dedicaba a las labores del hogar y que habitaba en la ciudad de Mérida en el mismo domicilio que la niña damnificada. Entonces, su única ocupación era estar al cuidado de su hija. El artículo cuarto de la Constitución Política de los Estados Unidos Mexicanos en su párrafo décimo establece como obligación de los ascendientes, tutores y custodios la preservación de los derechos de los niños. Ello, adminiculado con los artículos 1098, 1108 y 1111 del Código Civil del Estado, de los cuales se desprende, en una interpretación extensiva que verificó la sccF, la existencia normativa de una especie de autopuesta en peligro. Esta resulta cuando el menor de edad se ocasiona a sí mismo un

\footnotetext{
${ }^{35}$ Véase Paludi, Osvaldo, La relación de causalidad en la responsabilidad civil por hecho propio, Buenos Aires, Causa, 1976, p. 24. "Elaborada por Maximiliano von Buri [...] aparece fundada en la concepción filosófica de causa de John Stuart Mill: la causa pues, filosóficamente hablando es la suma de las condiciones positivas y negativas tomadas juntas, el total de las contingencias de toda naturaleza, que, siendo realizadas, hacen que siga el consiguiente".

${ }^{36}$ Véase Corcoy Bidasolo, MirentXu, El delito imprudente. Criterios de imputación del resultado, Buenos Aires, B de F, 2008, pp. 207-244.
} 
daño, y en cuyo caso este debe ser reparado, en primera instancia, por los responsables de su cuidado.

Lo anterior parte de que quienes ejercen la patria potestad son responsables de responder por los daños y perjuicios que ocasionen los actos de los menores bajo su poder, que habiten con ellos. Tales daños incluyen los que los menores se ocasionen a sí mismos. Así se formula la hipótesis de incurrir en falta de vigilancia respecto de la conducta de los menores, dado que padres o tutores son los sujetos garantes del bienestar de los menores, tanto por disposición del referido artículo cuarto constitucional como por imperativos morales y culturales.

La sccF infırió que se tenía a disposición toda la información (debido a su experiencia como adulto y madre) de que las calles que circundan a la zona, donde residen madre e hija, son transitadas por autobuses, lo cual potencia el riesgo de conducir una bicicleta, más aún sin supervisión.

Esta misma lógica se sigue en relación con la mecánica conductual de la parte demandada que, bajo la premisa del déficit probatorio en que incurrió, le fue reprochable no obrar diligentemente en la evitación del percance. Ello como consecuencia de que, al tratarse de profesionales en el ámbito del transporte público, tenían toda la información constitutiva de su deber de conducir conscientemente y de tener en óptimas condiciones el vehículo de mérito que permita la visión clara del camino de tránsito, el frenado eficiente del automotor ante una eventualidad y, en fin, todo lo que resulta de una razonable operación.

Es decir, la experiencia de la madre y de los profesionales ${ }^{37}$ del transporte, les permite conocer la información referente a los factores de riesgo que, de haber sido atendidos, hubiesen previsto el resultado. La previsibilidad se identifica con la probabilidad de lesión: la previsibilidad del resultado determina el ámbito que ha de abarcar el deber de cuidado; así, la infracción de este deber se discutirá solo cuando sea reconocible el riesgo. En el caso concreto, cualquier ser humano con sentido común ${ }^{38}$ reconocería como altamente riesgosa la actividad consistente en permitir la conducción de una bicicleta a un menor de edad por calles transitadas por automotores.

\footnotetext{
${ }^{37}$ En el proceso de concreción de la medida de cuidado se ha de atender a los principios de experiencia que vinculan determinados peligros a ciertas actividades y a las medidas de seguridad que ex ante aparecen más adecuadas para evitar dichos riesgos.

${ }^{38}$ La doctrina alude al concepto de hombre medio: "El hombre consciente y cuidadoso del sector del tráfico a que pertenece el autor [...] y, por tanto, el baremo para la determinación del deber objetivo de cuidado lo exigible a un hombre diligente en la situación concreta del autor [...] el hombre consciente, el hombre diligente, el hombre razonable, sirve como medida juridica para determinar el cuidado". Corcor BIDASOLO, MiRENTXU, El delito imprudente. Criterios de imputación del resultado, Buenos Aires, B de F, 2008, pp. 110-111.
} 
Ello es aún más relevante en aquellos ámbitos de actividad donde se falta a la observación de reglas técnicas, lo cual es atribuible a la empresa patrona, la cual tiene el deber de llevar a cabo un protocolo de mantenimiento constante del autobús utilizado por su empleado. Además, esto va aunado a la normatividad que establecen tanto la ley como el Reglamento de Tránsito y Vialidad del Estado de Yucatán, que determinan las pautas a seguir en la conducción de los automotores.

Finalmente, la evitabilidad de un hecho implica un elemento volitivo. Radica, pues, en la suma de conocimiento y previsión de un riesgo, a fin de que el resultado no se verifique. Quien conoce y prevé los riesgos de cierta actividad, y a pesar de ello los asume como improbables al confiar en que no sucederán, debe responder por los daños que en su caso se generen. De tal forma sucedió en la especie, pues, como se ha manifestado en líneas precedentes, tanto madre como conductor y empresa tenían la información del riesgo, pudieron preverlo y aun así confiaron en que no se generarían resultados dañosos.

En conclusión, para la SCCF, tales efectos son degradantes de la responsabilidad, al ser esta compartida tanto por la víctima como por el victimario, ${ }^{39}$ idea que acoge la Primera Sala de la scJn en su jurisprudencia. ${ }^{40}$

En la concurrencia de culpas se examina la aportación causal de cada una de las partes en el evento. Cuando esta aportación (conducta) es imprudente, su relevancia estará en atención a su eficacia y determinación exclusiva del resultado. Si se aprecia esa importancia vital en la producción del resultado, deberá tener unas consecuencias que se traducen, por una parte, en la degradación de la culpa del autor; por otra, en la ponderación del resarcimiento económico derivado de la responsabilidad civil ex delicto. ${ }^{41}$

Cuenta habida de lo anterior, la sccF utilizó el criterio de la teoría de la equivalencia de las condiciones (von Buri) y estimó que, en efecto, en el caso acontece la concurrencia de culpas. Resulta así que la responsabilidad en el hecho debía dividirse entre las tres condiciones efectivamente acreditadas (sea directamente o por déficits probatorios), las cuales tienen el mismo peso o valor; a saber: uno, falta de diligencia del chofer; dos, falta de diligencia de la empresa patrona, propietaria del vehículo automotor y tres, imprudencia temeraria de la madre de la menor, al permitir que esta condujera en la vía pública una bicicleta sin supervisión.

\footnotetext{
${ }^{39}$ Tamarit Sumalla, Josep M., La víctima en el derecho penal, Pamplona, Aranzadi,1998, p. 159.

${ }^{40}$ Tesis primera, 277/2014, Gaceta del Semanario Judicial de la Federación, Décima Época, julio de 2014, p. 167.

${ }^{41}$ Bonet Esteva, Margarita, La víctima del delito (la autopuesta en peligro como causa de exclusión del tipo de injusto), Madrid, McGraw Hill, 1999, p. 140.
} 
En ese sentido, la responsabilidad que a cada una de las partes correspondió se fijó en un tercio. Por tanto, las indemnizaciones atinentes al daño material exigido, con motivo de la imputación objetiva de los hechos, fue derivada por la SCCF a ser calculada en esa proporción en el incidente de liquidación que al efecto se aperture, a fin de ejecutar la sentencia.

En tales términos y en lo que interesa, fue resuelto el litigio de referencia: por ejecutoria de 5 de julio de 2016, el Tcc negó los correspondientes amparos (A.D 575/2015, A.D. 576/2015 y 576/2015) a las partes involucradas.

\section{Conclusión}

La autopuesta en peligro es una institución que se ha desarrollado en los últimos años en el derecho penal. Empero, la generación de riesgos en la sociedad actual y el planteamiento novedoso de la victimodogmática permiten que el derecho civil de daños reciba aquella figura con matices propios.

Ha quedado claramente demostrado que, como motivo de las ejecutorias federales que en el caso concreto influyeron en su decisión final, la sccF adoptó una especie de autopuesta en peligro como factor atenuante de la responsabilidad civil. Esta especie deriva de la concurrencia de culpas, en específico, cuando se incurre en la llamada culpa in vigilando por quien es sujeto garante del bienestar de un menor de edad.

Es interesante advertir el criterio equitativo con base en la teoría de la equivalencia de las condiciones, a partir de la cual se fijó la proporción de la culpa y la respectiva tasación de las indemnizaciones.

Esto se considera equitativo, ya que la conducta omisiva de la madre de la menor -vigilarla y cuidarla para evitar que jugara con la bicicleta en calles transitadas por vehículos de motor- puso en riesgo la vida e integridad física de la niña. Por tanto, su conducta es de igual magnitud que la de los dos demandados por no obrar con diligencia, puesto que ambas partes, con su proceder, pusieron en riesgo a la menor de edad.

Así, la autopuesta en peligro cobra identidad en el derecho civil, pues, ante su existencia comprobada en autos, atenúa y distribuye las responsabilidades entre los sujetos participantes en el evento dañoso. Esto a diferencia de lo que sucede en el derecho penal, en donde se torna como una causal de exclusión del injusto. 


\section{Referencias bibliográficas}

Alastuey Dobón, M. CARmen, La reparación a la víctima en el marco de las sanciones penales, Valencia, Tirant lo Blanch, 2000.

Bonet Esteva, Margarita, La víctima del delito (la autopuesta en peligro como causa de exclusión del tipo de injusto), Madrid, McGraw Hill, 1999.

Cancio Meliá, Manuel, Conducta de la víctima e imputación objetiva en Derecho Penal. Estudio sobre los ámbitos de responsabilidad de víctima y autor en actividades arriesgadas, Barcelona, J. M. Bosch Editor, 2001.

Corcoy Bidasolo, Mirentxu, El delito imprudente. Criterios de imputación del resultado, Buenos Aires, B de F, 2008.

González Cussac y Mira Benavent, “Ámbito de responsabilidad de la víctima y teoría de la imputación objetiva”, en La Ciencia del Derecho Penal ante el nuevo siglo, libro homenaje al profesor doctor don José Cerezo Mir, tomo 1, Madrid, Tecnos, 2002. Elías Azar, Édgar, Frases y expresiones latinas, México, Porrúa, 2006.

Jescheck, Hans Heinrich, Tratado de derecho penal. Parte general, Granada, Editorial Comares, 1993.

Landrove Díaz, Gerardo, La moderna victimología, Valencia, Tirant lo Blanch, 1998. López Monroy, José de Jesús, “Artículo 1910", Código Civil para el Distrito Federal en materia común y para toda la República en materia federal comentado. Libro cuarto, primera parte. 'De las obligaciones', tomo 4, México, Instituto de Investigaciones Jurídicas de la Universidad Nacional Autónoma de México Miguel Ángel Porrúa, 1990.

Neuman, Elías, Victimología. El rol de la víctima en los delitos convencionales y no convencionales, México, Cárdenas Editor, 1992.

Ontiveros Alonso, Miguel, Derecho Penal. Parte General, México, Ubijus, 2017.

Orellana Wiarco, Octavio Alberto, Teoría del delito. Sistemáticas Casualista, Finalista y Funcionalista, México, Porrúa, 2000.

Paludi, Osvaldo, La relación de causalidad en la responsabilidad civil por hecho propio, Buenos Aires, Causa, 1976.

Pavón Vasconcelos, Francisco, Derecho Penal Mexicano, México, Porrúa, 2005.

Pérez Fuentes, Gisela María (coord). Temas actuales de responsabilidad civil. México, Tirant lo Blanch, 2018.

Pérez Fuentes, Gisela María; Gallegos Pérez, Nidia del Carmen, "Clases de responsabilidad civil”, en Gisela María Pérez Fuentes (coord.), Temas actuales de responsabilidad civil, México, Tirant lo Blanch, 2018.

Petit, Eugene, Tratado elemental de Derecho Romano, México, Editora Nacional, 1966. Rivero Evia, Jorge, Fundamentos de Derecho Intercultural, México, Tirant lo Blanch, 2017.

Rodríguez Manzanera, Luis, Victimología. Estudio de la víctima, México, Porrúa, 2000. 
SÁnchez Zapata, Sebastián Felipe, Actuación de la víctima e imputación objetiva: comentario a la sentencia de la Corte Suprema de Justicia 36842 del 27 de noviembre de 2013, Nuevo Foro Penal, junio, 2014, vol. 10, núm. 82.

Silva SÁnchez, Jesús María, La expansión del derecho penal. Aspectos de la política criminal en las sociedades postindustriales, Madrid, Civitas, 2001.

Tamarit Sumalla, Josep M., La víctima en el derecho penal, Pamplona, Aranzadi, 1998. 